\section{Farm Machinery}

By C. Culpin. Pp. 405. (London : Crosby Lockwood and Son, Ltd., 1938.) 18s. net.

A TEXT-BOOK on modern farm machinery by A a British author was long overdue, and this book is a praiseworthy attempt to make good this deficiency. To-day there are few operations on farms to which machinery has not been applied, and an effort has been made to cover the whole field. In addition appendixes dealing with elementary prineiples of mechanics and prime movers have been added. These are well chosen, concise and clear.

The main subject is admirably marshalled but often details of design and operation are meagre; furthermore there is a lack of expression as to the true value of implements from the practical point of view.

One or two mistakes have been missed in proofreading and there are some statements in working descriptions that need correction. At p. 170 the bills of the knotting mechanism are said "to grasp the twine between the loop and the sheaf". This is incorrect, but the correct version is given in note 3 to Fig. 87 (p. 173). In dealing with milk coolers (p. 269) it is stated that with water coolers the water runs in copper tubes covered with heavily tinned corrugated metal. There are no tubes in corrugated coolers, the water being in direct internal contact with the corrugations. At the foot of the same page we find that "the refrigerant cools a solution of brine which is then used for cooling the commodity". Brine is not used in farm refrigerating coolers; they work by direct expansion.

In conclusion, while admiring Mr. Culpin's courage and devotion to the subject in which he lectures, we think that if more than a bird's-eye view of the subject is to be attempted, the task is a composite one to be handled by specialists rich in both practical and theoretical knowledge in their own particular branches. Nevertheless, we welcome this book as an introduction to further study.

C. E. E.

\section{The Microscopical Study of Drugs}

By Lilian A. Kay. Pp. viii $+228+47$ plates. (London : Baillière, Tindall and Cox, 1938.) 10s. $6 d$.

$\mathrm{T}$ HIS book comprises a series of forty schedules, each designed to occupy a three-hour practical period, intended for students following courses of training in pharmacognosy where a knowledge of microscopy of drugs, starches, textile fibres, etc., is required. Introductory chapters deal with such fundamental subjects as the technique of drawing of microscopic objects, micro-measurement, maceration, and micro-chemical tests. Then follow directions for the detailed examination of surgical dressings, fabrics and organized drugs. Finally are given methods and examples of quantitative analysis of mixed and adulterated powders, and an appendix of useful information.

Practically all the above is already covered for students by Mr. T. E. Wallis in his "Practical Pharmacognosy". The chief advantage of Miss Kay's book lies in the illustrations, in which are set forth the anatomical structure and histology of organized drugs prescribed for microscopical study in the syllabus of the Pharmaceutical Chemist Qualifying Examination of the Pharmaceutical Society of Great Britain. These drawings are generally faithful representations of what should be seen under the microscope, and will be appreciated by students, especially those who have not had the advantage of a sufficient botanical training.

Certain corrections will have to be made in a new edition, notably the references to the perimedullary phloem in the three solanaceous leaves, confused with the endodermis; and to the vascular bundles of fennel fruit, named primary ridges.

W. O. Howarth.

\section{La Biologie des Orthoptères}

Par Lucien Chopard. (Encyclopédie entomologique, Tome 20.) Pp. $542+5$ plates. (Paris: Paul Lechevalier, 1938.) 250 francs.

7 HE name of Dr. Lucien Chopard is in itself a 1 guarantee of the value and reliability of this work. It constitutes the most up-to-date and comprehensive account of the order of insects with which it is concerned. The work is arranged in thirteen chapters, each accompanied by a selective bibliography of publications relating to it. Chapter i deals with geographical distribution, which also takes into account insular faunas and distribution in geological periods. Reproductive phenomena occupy two chapters, and these are followed by chapters on development and activity, on sound-production, on autotomy and regeneration, and on reflexes and means of defence. Among other chapters, those on variation and heredity and on rudiments of social life are also noteworthy.

The book is a veritable storehouse of biological information and will prove valuable to workers in many fields. Its illustrations number 453 figures, all of which are clearly reproduced. The book is well supplied with both a general and an author index.

A. D. I.

\section{St. Thomas's Hospital Reports}

Editors: Prof. O. L. V. S. De Wesselow, C. Max Page, assisted by N. R. Barrett, Dr. J. St. C. Elkington, Dr. A. J. Wrigley. Second Series, Vol. 3. Pp. $240+23$ plates. (London : St. Thomas's Hospital, 1938.) $10 s$.

7 HIS volume contains thirty-nine articles from 1 various departments of the Hospital, of which the following are examples: "A Complete Clinical and Pathological History of One of the Earliest Cases of X-Ray Carcinoma", by the late Prof. Leonard S. Dudgeon; "The Biological Test for Hodgkin's Disease", by Dr. D. P. King; "Vitamins in the Treatment of Rheumatism in Children", by Drs. H. W. Everley Jones and S. Taylor ; "The Functions of a Psychiatric Department for Children in a General Teaching Hospital", by Dr. W. H. de B. Hubert, and "The Evaluation of the Modern Treatment of Gonorrhœa", by Dr. T. Anwyl-Davies.

The papers, which are well printed and illustrated, are all of a high scientific standard. 